\title{
CHAPTER 7 \\ Brain-to-Brain Interfaces and the Role of Language in Distributing Agency
}

\author{
MARK DINGEMANSE
}

\section{A VISION OF THE FUTURE}

In 1994, Nobel Prize-winning physicist Murray Gell-Mann wrote, "Some day, for better or for worse ... a human being could be wired directly to an advanced computer, (not through spoken language or an interface like a console), and by means of that computer to one or more other human beings. Thoughts and feelings would be completely shared, with none of the selectivity or deception that language permits" (Gell-Mann 1994:24). Only two decades later, the scientific literature records the first proofs of concept of such brain-to-brain interfaces (Grau et al. 2014; Rao et al. 2014), touting a new era in which brains are directly connected and promising to "revolutionize how humans communicate and collaborate" (Rao et al. 2014:11). This chapter explores some of the assumptions about human interaction implicit in this line of research, and juxtaposes them with a view of language as the ultimate brain-to-brain interface: an interactive, selective, negotiable system that enables individuals with separate bodies to achieve joint agency without giving up behavioral flexibility and social accountability.

A key step on the way to brain-to-brain interfaces has been the development of brain-to-machine interfaces: devices that can be controlled with neural activity. The attraction of such interfaces is that they can bypass some of the constraints of human bodies, a goal that resonates in popular 
culture but also offers practical applications, for instance in the form of neurally controlled prosthetic devices that enable paralyzed patients to regain limb functions. A more ambitious program is to link such brain-to-machine interfaces together to yield brain-to-brain interfaces (Nicolelis 2013). The applications, medical or otherwise, are somewhat less clear here, but a commonly stated interest is to bypass verbal communication in order to avoid its articulatory bottlenecks and expressive limitations (Rao et al. 2014) or indeed its possibilities for selectivity and deception (Gell-Mann 1994).

Implicit in these ideals of sidestepping the constraints of bodies and language is a narrow view of human agency and communication, and a limited recognition of how material and cultural artifacts have long extended our minds (Clark and Chalmers 1998). "Can information that is available in the brain be transferred directly in the form of the neural code, bypassing language altogether?" ask Rao et al. (2014:1). This reveals a sender-receiver model of communication in which externalization is seen as a mere obstacle to the goal of sharing private processesthe possibility that it may provide much-needed filters and calibration mechanisms is not considered. Rao et al.'s experiment consists of recording brain activity in one person using electro-encephalography and delivering it to another person using a transcranial magnetic stimulation device positioned such that a pulse results in an involuntary upward jerk of the hand. The other has no choice, but is controlled by brute force. This is communication stripped of any possibilities for negotiating joint commitment or shared intentionality (Gilbert 1989). It is akin to pushing someone out of the room rather than persuading him or her to leave.

Current conceptions of brain-to-brain interfaces thus appear to be more about the involuntary unloading of information than about the coconstruction of shared understanding, and more about control by brute force than about cooperation by consent-all at a loss of individual agency. Collaboration, of course, always involves some redistribution of individual agency to a larger social unit, creating joint agency. How is this achieved? A brain-to-brain interface implements it physically; language does it socially. The two need not exclude each other. A goal of this chapter is to put forward some insights about human language that may be incorporated in the design of ethically responsible brain-to-brain interfaces (Trimper et al. 2014).

\section{LANGUAGE AND HUMAN AGENCY}

To understand how language shapes and constrains distributed agency, there is no better place to look than its primary ecological niche: everyday 
conversation. The following fragment was recorded in Ghana, but its analysis draws on insights that apply to social interaction everywhere (Sacks 1992). Some family members have just finished processing some newly harvested maize and are now preparing to play a board game. A large metal tub holding the maize is still in the way, making it hard for others to join the game.

Siwu (Neighbours_3093575)

1 ((Ben is holding a board game for four; a large metal tub with processed maize stands in the way of others joining))

2 Sesi kãrãnpo laa puta lò yedza ìyo katõ mmo. right I'll lift this and put it in storage there

3 Ben be tè mì puta mì yedza iyo:? what are you going to put in storage?

4 Sesi àtita the maize

5 Ben ta mà ba mà su àtitabi wangbe kõrõkõrõ. this maize will be picked up right away

6 Sesi ã, ma kelè gu kala ah, they're taking it down ((to the lower end of the village)) ((some intervening turns omitted))

12 Sesi غ̀h, nyua bò Afua. uh, wait, Afua

13 Afua ((looks up))

14 Sesi mi məع gu mè si bò su bò sia ngbe. grab this with me so we put it right here

15 ((1.6 seconds of silence)

16 Sesi bò su bo yedza i kurue ne te mi ba mia se ngbe mi pe irà̀ ni. let us put this to the side so you can come and play this thing

17 ((Sesi \& Afua lift tub together and place it one meter to the side))

18 Sesi kaile. that's good.

19 ((people sit down to play the game))

Sesi offers to put away the tub in the storage room. Ben asks for clarification, and when Sesi makes clear he refers to the maize, Ben notes that it will be taken elsewhere soon. This leads to a slight change of plans. Now 
all Sesi needs to do is move the tub to the side. He recruits the help of his sibling Afua. Once the obstacle is out of the way, people sit down to play the game. Exchanges like this happen all over the world every day-and it is in this kind of context that we see some of the most fundamental roles of language in social life.

Most importantly, language helps distribute agency. Take Sesi's request for help (lines 12-18): he addresses Afua by name to secure her attention, then produces a first version of the request. When there is no immediate uptake, he reformulates his request, adding a reason which turns it from a mere practical matter into a joint project that may also benefit her ("let's put this to the side so you can come and play this thing," line 16). His actions show that language provides a systematic organization of linguistic resources to interactively manage the many concerns at play when one person asks another to do something. The ultimate effect is that Sesi succeeds in recruiting Afua's body as a "tool" for carrying out a joint action. This is somewhat like the participants in the Rao et al. (2014) experiment, but with the crucial difference that it is jointly negotiated rather than achieved by brute force. Two features in particular help language distribute agency: its selectivity and its negotiability.

The selectivity of language manifests itself in two ways. First, speakers can select the linguistic means for making their ideas public, allowing them to foreground or background certain informational or relational concerns. To this end, language offers a large and renewable supply of words, expressions, and conversational structures. Sesi can refer to the tub of maize with "this" (relying on shared context) or with "the maize" (spelling out the underspecified reference). He can refer to his sister as "Afua" (highlighting her status as an individual) but also include her in the pronoun "us" (highlighting her status as part of a joint social unit created in that very moment). This selectivity makes language highly efficient by enabling it to be underspecified when possible, yet specifiable when necessary (Levinson 2000). A second sense in which language is selective is that speakers can select what to make public and what to keep private. Language provides us with ways to control and filter what we share with whom. Perhaps it is this sense of selectivity that Gell-Mann deplored, as it opens up the possibility for deception. However, this is easily outweighed by the social benefits: some things are better left unsaid. More generally, sharing and withholding information are among the most important ways in which we manage our social relationships. The selectivity of public language means that it offers a set of filters through which we can efficiently and tactfully connect private worlds.

The other key feature of how language distributes agency is its negotiability: the fact that meaning and mutual understanding are always open to 
negotiation. Mutual understanding between people is built bit by bit in conversation. Every turn at talk is a social action as well as a take on the social action implemented by the prior one. So Sesi's "ah, they're taking it down" displays one possible interpretation of Ben's "this maize will be picked up right away" (lines 5-6) in an instance of the common process of grounding (Clark and Brennan 1991). A more explicit case of the negotiation of understanding is Ben's request for clarification and Sesi's response to it (lines 3-4). This illustrates "conversational repair," the machinery that people use to deal with small but frequent rifts in mutual understanding (Dingemanse et al. 2015).

Don't such misunderstandings exemplify the kind of imperfections that brain-to-brain interfaces aim to rid us of? To the contrary: it is precisely in the tussles of negotiating mutual understanding that language affords a great degree of agency. Here, for instance, conversational repair provides Ben with a way to have a hand in subtly revising Sesi's plans without unilaterally imposing another course of action. In other instances, repair can provide ways to resist something (such as divulging personal information or agreeing with another's statement), empowering people to commit to different degrees of participation without rupturing the social fabric (Sacks 1992). The interactive construction of shared understanding provides people at every turn with opportunities for signaling consent or dissent. This amounts to a set of checks and balances through which people can calibrate and revise the inferences that are constantly made.

People have separate bodies. While brain-to-brain interfaces may somewhat dilute this separateness, language has long bridged it. Never merely individuals, we are always part of a wide range of larger social units, some fleeting and diffuse (like the 4-second long unit of Sesi and Afua moving the tub out of the way, or the more dispersed unit of "readers of this essay") and others more strong and durable (like a close friendship or a kin relation). Language is the main tool through which we are able to navigate this mosaic of social relations, constantly switching frames between "me" and the many different senses of "us" (Enfield 2013). Language allows us to maintain our individual identity and agency while merging and joining forces at other levels.

\section{TOWARD A MORE PRODUCTIVE VIEW OF LANGUAGE FOR BRAIN-TO-BRAIN INTERFACES}

Current conceptions of brain-to-brain interfaces strive to connect brains directly, "bypassing language altogether" (Rao et al. 2014), hoping to bring about the complete sharing of thoughts and feelings as Gell-Mann envisioned 
it. A recurrent dream in this work is the prospect of a "mind meld," in which a super-network of brains may come to be the substrate for something like a meta-consciousness (Nicolelis 2013). From a biological perspective this is not novel. Mind melds - or complex networks in which large numbers of individual agents together achieve a form of sentience-have independently arisen several times in evolution, for instance in eusocial insect societies and in cellular slime molds, the latter capable of impressive feats in maze-solving. The real challenge for brain-to-brain interfaces is not to achieve some interlinking of brains; it is to harness this technology in a way that does not reduce human participants to the level of amoeba in a slime mold.

Seen in this light, the selectivity and negotiability of language are not bugs, they are features. Thanks to these features of language, we can maintain a complex web of social relations by managing what we share with whom, and we can join forces in larger social units without indefinitely relinquishing individual agency. To throw this into sharper relief, consider what happens when selectivity and negotiability are systematically diminished or punished, as in religious indoctrination or interrogation under torture. Here, the very defining features of individual agency are taken away, and it is no coincidence that we describe such circumstances as dehumanizing or inhumane. Language is what makes us human. It is not merely a conduit for information. We might try exchanging it for a high-throughput physical connection to optimize the flow of some types of information-but we would do so at the tremendous cost of throwing away a rich infrastructure for organizing social agency.

Could brain-to-brain interfaces be designed in a way that incorporates this infrastructure? None of the points made above logically depend on the spoken, face-to-face version of language that is its most prevalent form today. In fact, language is modality-independent to some degree, as shown by the fact that it can be realized wholly visually as in the signed languages of the deaf. So it is not inconceivable that there can be some useful form of social interaction in the substrate of brain-to-brain interfaces. Whatever the modality of communication, the two design features that matter most for creating a truly humane form of brain-to-brain interfaces are: (1) selectivity, giving people control over the relation between public words and private worlds; and (2) negotiability, giving people systematic opportunities for calibrating and revising joint commitments.

\section{CONCLUSIONS}

The Hitchhiker's Guide to the Galaxy records the case of the Belcerebon people of Kakrafoon, who were inflicted by a Galactic Tribunal with "that 
most cruel of social diseases, telepathy" (Adams 2002[1980]:252-3). It was a punishment with unforeseen consequences: "in order to prevent themselves broadcasting every slightest thought that crosses their minds ... they now have to talk very loudly and continuously about the weather, their little aches and pains, the match this afternoon, and what a noisy place Kakrafoon has suddenly become." Current conceptions of brain-tobrain interfaces appear to be on their way to replicating the fate of the Belcerebon people. In contrast, the human condition is enabled by a flexible communication system that saves us from an all too unconstrained sharing of private processes while still helping us to cooperate and achieve shared goals in ways unmatched anywhere in the animal kingdom.

Brain-to-brain interfaces are often presented as a system for sharing information and organizing joint action that is superior to natural language. However, directly connecting one individual's mental life to that of another has the effect of robbing both of a great degree of individual agency. There may be gains in agency elsewhere, but without the checks and balances provided by a system like language, they will likely lie at levels beyond the direct control of the individuals. Language serves as a filter between the private and the public, and as an infrastructure for negotiating consent and dissent. As research into brain-to-brain interfaces matures, it is my hope that it will find ways to incorporate selectivity and negotiability, so as to extend human agency in meaningful ways.

\section{ACKNOWLEDGMENTS}

Thanks to Nick Enfield, Steve Levinson, and Paul Kockelman for helping me develop my thinking on the topics raised here. I received helpful comments on draft versions from Nick Enfield and Roel Willems, and I thank other contributors to the Foundations of Social Agency meeting at Ringberg Castle for stimulating interactions. I gratefully acknowledge the support of an NWO Veni grant and of the Max Planck Society for the Advancement of Science.

\section{REFERENCES}

Adams, Douglas. 2002. The Ultimate Hitchhiker's Guide to the Galaxy. New York: Del Rey.

Clark, Andy, and David Chalmers. 1998. “The Extended Mind.” Analysis 58(1): 7-19.

Clark, Herbert H., and Susan E. Brennan. 1991. "Grounding in Communication."

In Perspectives on Socially Shared Cognition, edited by Lauren B. Resnick, J. M.

Levine, and S. D. Teasley, 13:127-149. Washington, DC: APA Books. 
Dingemanse, Mark, Seán G. Roberts, Julija Baranova, Joe Blythe, Paul Drew, Simeon Floyd, Rosa S. Gisladottir, Kobin H. Kendrick, Stephen C. Levinson, Elizabeth Manrique, Giovanni Rossi, N. J. Enfield. 2015. "Universal Principles in the Repair of Communication Problems." PLOS ONE 10(9): e0136100. doi:10.1371/journal.pone.0136100.

Enfield, N. J. 2013. Relationship Thinking: Agency, Enchrony, and Human Sociality. Oxford: Oxford University Press.

Gell-Mann, Murray. 1994. The Quark and the Jaguar: Adventures in the Simple and the Complex. New York: W. H. Freeman.

Gilbert, Margaret. 1989. On Social Facts. London/New York: Routledge.

Grau, Carles, Romuald Ginhoux, Alejandro Riera, Thanh Lam Nguyen, Hubert Chauvat, Michel Berg, Julià L. Amengual, Alvaro Pascual-Leone, and Giulio Ruffini. 2014. "Conscious Brain-to-Brain Communication in Humans Using Non-Invasive Technologies.” PLOS ONE 9(8): e105225. doi:10.1371/journal. pone.0105225.

Levinson, Stephen C. 2000. Presumptive Meanings: The Theory of Generalized Conversational Implicature. Cambridge, MA: MIT Press.

Nicolelis, Miguel. 2013. Beyond Boundaries: The New Neuroscience of Connecting Brains with Machines - and How It Will Change Our Lives. New York: Henry Holt and Company.

Rao, Rajesh P. N., Andrea Stocco, Matthew Bryan, Devapratim Sarma, Tiffany M. Youngquist, Joseph Wu, and Chantel S. Prat. 2014. "A Direct Brain-to-Brain Interface in Humans." PLOS ONE 9(11): e111332. doi:10.1371/journal. pone.0111332.

Sacks, Harvey. 1992. Lectures on Conversation. 2 vols. London: Blackwell.

Trimper, John B., Paul Root Wolpe, and Karen S. Rommelfanger. 2014. "When 'I' Becomes 'We': Ethical Implications of Emerging Brain-to-Brain Interfacing Technologies." Frontiers in Neuroengineering 7: 4. doi:10.3389/ fneng.2014.00004. 